\title{
Photodegradation of Sulfadiazine in Aqueous Solution and the Affecting Factors
}

\author{
Xuesen Bian and Jibing Zhang \\ Nanjing Institute of Environmental Sciences, Ministry of Environmental Protection of the People's Republic of China, \\ 8 Jiangwangmiao Street, Nanjing 210042, China \\ Correspondence should be addressed to Jibing Zhang; zhangjb@ofdc.org.cn
}

Received 29 March 2016; Revised 7 June 2016; Accepted 13 June 2016

Academic Editor: Athanasios Katsoyiannis

Copyright (c) 2016 X. Bian and J. Zhang. This is an open access article distributed under the Creative Commons Attribution License, which permits unrestricted use, distribution, and reproduction in any medium, provided the original work is properly cited.

Knowledge about photochemical behavior of sulfonamides under UV light is limited. In this study, photodegradation of sulfadiazine in water by ultraviolet (UV) light was studied using a $300 \mathrm{~W}, 365 \mathrm{~nm}$ UV lamp. The degradation process followed well the first-order kinetics, with a half-life of $9.76 \mathrm{~min}$ in water with air saturation. The photodegradation was slower at acidic $\mathrm{pH} 4.52 \mathrm{than}$ at $\mathrm{pH}$ 6.98 and $\mathrm{pH}$ 8.90. Addition of $\mathrm{H}_{2} \mathrm{O}_{2}$ and nitrate enhanced the photodegradation rate, while addition of ethanol, nitrite, sulfate, and bicarbonate depressed the reaction rate. This study suggested that sulfadiazine photodegradation under UV light is generally favored by the attack of hydroxyl radicals.

\section{Introduction}

Antibiotics are a sort of organic compounds synthesized by industry or generated by organisms including microorganisms, plants, and animals, in their life activities, which could selectively depress or influence functions of other organisms at low or even micro level concentrations. In the last six decades large quantities of antibiotics were employed worldwide for prevention or treatment of diseases of both humans and livestock, as well as for some nontherapeutic purposes such as promoting the growth of cattle [1]. Antibiotics can enter the environment through many ways like irrigation using sewage water, disposal of unused drugs, land application of biosolids, and animal manure [1] and have been found ubiquitously in different environmental media like water [2], sediments [3], soils [4], excrements of organisms [4], and so forth. The antibiotics in the environment could lead to various negative effects such as microbial resistances, which have been regarded as a global problem, changes of indigenous microbial composition [5], disturbances of plant growth [6], acute or chronic toxicities on aquatic species [7], and the potential adverse effects on humans through food chains [8]. Therefore, study on the fate of antibiotics in the environment has been receiving worldwide concerns $[9,10]$.
Sulfadiazine is one of the commonly used sulfonamide antibiotics. Sulfonamides are frequently employed as medicines to treat both human and livestock diseases. For example, the annual usages as veterinary medicine were $78 \mathrm{t}$ in the European Union (1999) and $94 \mathrm{t}$ in England (2000) [9]. Reported half-lives of such chemicals were $<8 \mathrm{~d}$ to $30 \mathrm{~d}$ in manure [11] and $>21 \mathrm{~d}$ to $100 \mathrm{~d}$ in water or sediments [10]. The environmental behaviors like sorption and biodegradation were already documented for some of these chemicals, but the removal efficiency of these chemicals from aqueous phase seemed to be quite limited or even ignorable [12-14]. Photodegradation is one important degradation process in natural environment. Photodegradation, both direct (reaction between substrates and photons) and indirect (reaction between substrates and reactive species formed by photons), of sulfadiazine under natural or simulated sunlight was investigated by previous studies $[15,16]$. The expected environmental half-lives were 4.7-65.9 days in Kolkata, India, and Berlin, Germany, in different seasons [15] and 28-5200 h through various degradation pathways in near surface waters in Lake Josephine [16]. But in other ways, the photodegradation behavior under pure UV light has not yet been reported to our knowledge. UV occupies about 7 percent in the sunlight irradiation energy, and it is 


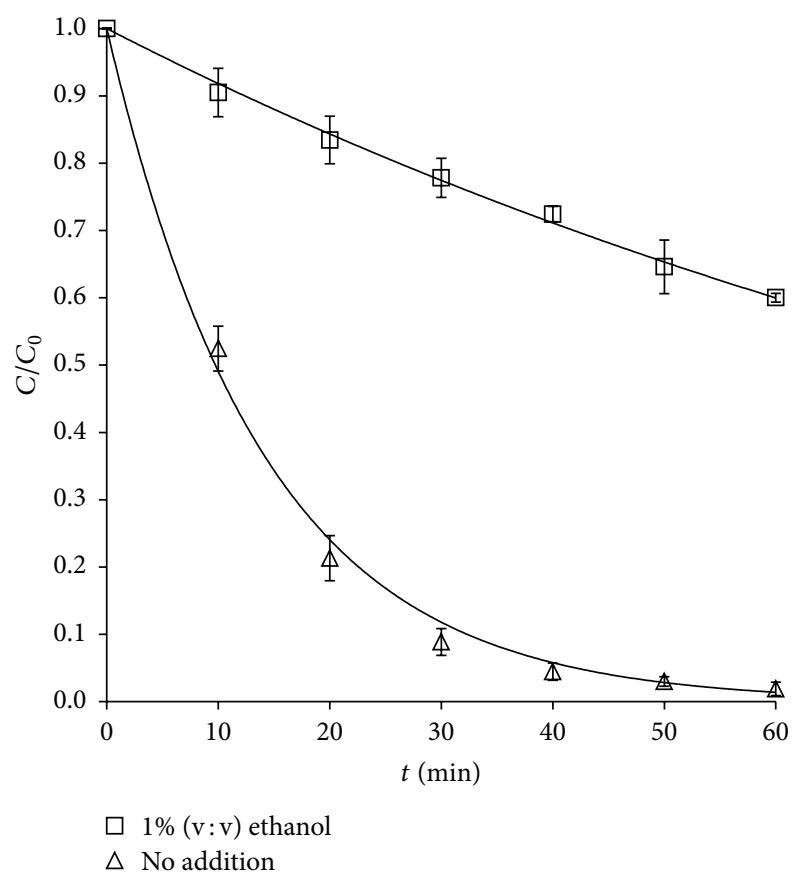

FIGURE 1: Photodegradation of $11 \mathrm{mg} \cdot \mathrm{L}^{-1}$ sulfadiazine in ultrapure water under UV $365 \mathrm{~nm}(300 \mathrm{~W})$ with pumping-in of air in the presence and absence of $1 \%$ ethanol. The solid lines represent the modeling results of first-order kinetics $\left(C_{t} / C_{0}=e^{-k t}\right)$.

also used artificially to remove the microorganism toxicity of antibiotics, as a pretreatment method to make the activated sludge system in the following step run more efficiently. Therefore, results from UV photodegradation study not only will be useful to learn the behavior of photolysis by ultraviolet in water environment but also will be helpful to the design of the artificial wastewater treatment system through UV photolysis of such chemicals. This work is designed to study kinetics and possible mechanisms of sulfadiazine photodecomposition under pure UV, by investigating the influences of some common affecting factors.

\section{Experimental}

2.1. General. Sulfadiazine (99.6\% purity) was purchased from Sigma, USA. Other chemicals were at least of analytical grade and used without further purification.

The photoreactor was designed according to Jiang et al. [17]. The ultraviolet lamp ( $365 \mathrm{~nm} ; 300 \mathrm{~W})$ used in our experiments was purchased from the Xujiang Electromechanical Plant, Nanjing, China.

The HPLC system used in this study was an Agilent 1200 series HPLC system, which consisted of a G1322 A degasser, a G1311 A Quat Pump, a G1329 A thermostatted autosampler, and a G1316A column oven. The column for separation was Agilent Eclipse XDB-C18 $(5 \mu \mathrm{m} ; 4.6 \times 250 \mathrm{~mm})$.

2.2. Photodegradation Procedures and HPLC Analysis. About $11 \mathrm{mg} \cdot \mathrm{L}^{-1}$ sulfadiazine solution was prepared by dissolving $5.5 \mathrm{mg}$ sulfadiazine into $500 \mathrm{~mL}$ ultrapure water and was transferred into the glass reactor. To investigate the effects of affecting factors, additives were introduced, respectively, at the following concentrations: ethanol of $1 \%$ in volume of the solution, $43.8 \mathrm{mg} \cdot \mathrm{L}^{-1} \mathrm{H}_{2} \mathrm{O}_{2}$, sodium salts with $0.05 \mathrm{mM}$ $\mathrm{NO}_{2}{ }^{-}, 0.5 \mathrm{mM} \mathrm{NO}_{3}{ }^{-}, 1 \mathrm{mM}$ and $5 \mathrm{mM} \mathrm{SO}_{4}{ }^{2-}$, and $0.5,2.4$, and $11.9 \mathrm{mM} \mathrm{HCO}_{3}{ }^{-}$. The $\mathrm{pH}$ effect was studied by adding appropriate $\mathrm{HCl}$ or $\mathrm{NaOH}$. The first sample (defined as time 0 ) was taken immediately after the addition of one of these chemicals to the reactor. The ultraviolet lamp in the central hollow was then turned on, and photodegradation process was started. All experimental processes were accompanied by vigorous stirring and air-pumping into the system at $1 \mathrm{~mL} \cdot \mathrm{s}^{-1}$, except that, in the case of nitrogen effect, $\mathrm{N}_{2}$ instead of air was pumped in. Sampling was performed at different time intervals. The samples were frozen at $-20^{\circ} \mathrm{C}$ until analysis. The mobile phase used for HPLC analysis of sulfadiazine was methanol : water $=30: 70(\mathrm{v}: \mathrm{v})$ isocratically running at a flow rate of $1 \mathrm{~mL} \cdot \mathrm{min}^{-1}$. Calibration curves were used to read the values of sulfadiazine for all samples, and the quality control of HPLC was carried out by injecting and analyzing the lowest and highest concentrations of standard sulfadiazine solutions at the beginnings and ends of all analytical circles. Control experiment without any irradiation was carried out under the same conditions. All experiments were performed at least in duplicate.

\section{Results and Discussion}

3.1. Effect of Ethanol. Control experiment under dark conditions showed ignorable disappearance of sulfadiazine in the solution (data not shown), indicating that the compound was stable in the dark; that is, hydrolysis of sulfadiazine was not significant, which is in agreement with the observations of Boreen et al. [18], who found that most sulfa drugs were stable in solutions of various $\mathrm{pH}$ values.

Under radiation, sulfadiazine in pure water was degraded by 99 percent in one hour with a half-life of $9.76 \mathrm{~min}$ (Figure 1). The first-order kinetic model $\left(C_{t} / C_{0}=e^{-k t}\right)$ was used to describe the degradation process under various conditions, resulting in a relationship of the ratio of remaining sulfadiazine $(y)$ versus time $(x)$ as $y=e^{-0.071 x}\left(R^{2}=0.98\right.$, Figure 1 and Table 1). Sulfadiazine in natural water might be degraded by irradiation through both direct and indirect ways. The UVVis absorption spectrum of sulfadiazine has a tailing band in the region of wavelength over $290 \mathrm{~nm}$ [15], which suggests that the way of direct photolysis for this compound cannot be preexcluded [15]. When ethanol, a hydroxyl scavenger, was added to the solution, $k$ value decreased to $0.009\left(R^{2}=1.00\right)$. This indicates that the dominant mechanism for sulfadiazine degradation might be the attack of hydroxyl radicals and therefore that degradation of sulfadiazine through the direct absorption of light was limited to a very small extent. The photolysis of water by UV irradiation may involve 25-30 reactions and 14 different species including $\mathrm{H}^{\circ}, \mathrm{HO}_{2}{ }^{\circ}$, and ${ }^{\circ} \mathrm{OH}[19]$. Under the radiation of a xenon lamp, sulfadiazine in pure water had a rather longer half-life $(32 \mathrm{~h})$ with $k$ value of 0.0094 [15]. 
TABLE 1: First-order kinetic constants $k$ of sulfadiazine photodegradation in ultrapure water irradiated by UV light of $365 \mathrm{~nm}$ and $300 \mathrm{~W}$ with air pumping in (except the condition of $\mathrm{N}_{2}$ instead) under various conditions.

\begin{tabular}{lcc}
\hline Condition & $k$ & $R^{2}$ \\
\hline Without addition (only sulfadiazine in $\left.\mathrm{H}_{2} \mathrm{O}\right)$ & 0.071 & 0.98 \\
Plus $1 \%(\mathrm{~V}: \mathrm{V})$ ethanol & 0.009 & 1.00 \\
With nitrogen instead of air & 0.045 & 1.00 \\
Plus $43.8 \mathrm{mg} \cdot \mathrm{L}^{-1} \mathrm{H}_{2} \mathrm{O}_{2}$ & 0.13 & 1.00 \\
Plus 0.05 $\mathrm{mM} \mathrm{NO}_{2}{ }^{-}$ & 0.034 & 0.84 \\
Plus 0.5 $\mathrm{m} \mathrm{N} \mathrm{NO}_{3}{ }^{-}$ & 0.1 & 0.95 \\
Plus $1 \mathrm{mM} \mathrm{SO}_{4}{ }^{2-}$ & 0.054 & 0.95 \\
Plus 5 $\mathrm{mM} \mathrm{SO}_{4}{ }^{2-}$ & 0.057 & 0.96 \\
Plus 0.5 $\mathrm{mM} \mathrm{HCO}_{3}{ }^{-}$ & 0.017 & 0.89 \\
Plus 2.4 $\mathrm{mM} \mathrm{HCO}_{3}^{-}$ & 0.042 & 0.93 \\
Plus $11.9 \mathrm{mM} \mathrm{HCO}_{3}{ }^{-}$ & 0.046 & 0.96 \\
At pH 4.52 & 0.046 & 0.91 \\
At pH 6.98 & 0.065 & 0.98 \\
At pH 8.20 & 0.057 & 0.94 \\
\hline
\end{tabular}

3.2. Effect of $\mathrm{N}_{2} / \mathrm{H}_{2} \mathrm{O}_{2}$. When $\mathrm{N}_{2}$ instead of air was pumped into the solution, degradation of sulfadiazine was obviously slowed down and the kinetic equation varied to $C_{t} / C_{0}=$ $e^{-0.045 t}\left(R^{2}=1.00\right.$, Table 1$)$. The important role of oxygen was also observed in $\mathrm{TiO}_{2}$ photocatalytic degradation of 2,4dichlorophenol and cyclohexane [20,21]. The involvement of air might also be one reason for the much higher rate of sulfadiazine photodegradation observed by us than that by Sukul et al. [15], supporting again that this reaction was favored mainly by ${ }^{\circ} \mathrm{OH}$ in the system.

$\mathrm{H}_{2} \mathrm{O}_{2}$ can be photocleaved to two hydroxyl radicals by homogeneous crack $[22,23]$ :

$$
\mathrm{H}_{2} \mathrm{O}_{2}+h v \longrightarrow 2^{\circ} \mathrm{OH}
$$

Therefore $\mathrm{H}_{2} \mathrm{O}_{2}$ can significantly enhance reaction rates. A cleaning technology by advanced oxidation processes (AOPs) has been developed to utilize $\mathrm{H}_{2} \mathrm{O}_{2} / \mathrm{UV}$ or $\mathrm{Fe}^{2+} / \mathrm{H}_{2} \mathrm{O}_{2} / \mathrm{UV}$ as the source of hydroxyl radicals $[22,23]$. When $43.8 \mathrm{mg} \cdot \mathrm{L}^{-1}$ $\mathrm{H}_{2} \mathrm{O}_{2}$ was added to our system, the first-order constant rate of sulfadiazine degradation increased to $0.13\left(R^{2}=1.00\right)$, being almost two times of that under air alone (0.071) (Table 1$)$. The promoting effect by $\mathrm{H}_{2} \mathrm{O}_{2}$ was also reported in sulfadiazine sunlight photodegradation by Sukul et al. [15].

3.3. Effect of Nitrate and Nitrite. Nitrite in the water environment might come from various sources like photodegradation of DOM (dissolved organic matter), oxidation of ammonia, and organic $\mathrm{N}$ and can be oxidized to nitrate through different pathways [24]. Both anions are commonly existing in natural water and have potentials to affect photodegradation behavior of some chemicals [24-28]. Table 1 shows that the degradation rate of sulfadiazine was enhanced from 0.071 to $0.10\left(R^{2}=0.95\right)$ when nitrate was added into the solution. This is because nitrate can be photolyzed to nitroso and negative oxygen ions and the latter further combined with $\mathrm{H}^{+}$to form ${ }^{\circ} \mathrm{OH}[26]$ :

$$
\begin{gathered}
\mathrm{NO}_{3}{ }^{-}+h v \longrightarrow{ }^{\circ} \mathrm{NO}_{2}+\mathrm{O}^{\bullet-} \\
\mathrm{O}^{\bullet-}+\mathrm{H}^{+} \longleftrightarrow{ }^{\bullet} \mathrm{OH}
\end{gathered}
$$

The promoting effects of nitrate on photodegradation have also been observed for Diuron [26]. Lam and coworkers found that nitrate significantly enhanced the photodegradation rates of atrazine, bensulfuron methyl, fluometuron, and hexazinone in solutions containing low concentrations of color DOM irradiated by Xe lamp, and a significantly positively proportional correlation $\left(R^{2}>0.99\right)$ was observed between nitrate concentration and $k_{\text {obs }}$ in synthetic field water matrixes [29]. However, nitrate played an almost negligible role in electrochemically assisted $\mathrm{TiO}_{2}$ photocatalytic degradation of methyl orange [28], probably because in a heterogeneous system photons were preferentially absorbed by solid particles like $\mathrm{TiO}_{2}$ and therefore the sensitization of chemicals dissolved in liquid phase cannot be activated [28], while in a homogeneous system light energy can be distributed more evenly.

Nitrite is also considered as one source of ${ }^{\circ} \mathrm{OH}$ in a photolytic system and may be comparably or even more effective compared with nitrate in some surface water samples $[24,30]$. But in our study, the addition of $0.05 \mathrm{mM}$ nitrite resulted in a marked decrease of the rate constant from 0.071 $\left(R^{2}=0.98\right)$ to $0.034\left(R^{2}=0.84\right)$ (Table 1$)$. In addition to acting as ${ }^{\circ} \mathrm{OH}$ source, nitrite might also be a scavenger for $\cdot \mathrm{OH}$ according to the following equation [24]:

$$
\mathrm{NO}_{2}{ }^{-}+{ }^{\bullet} \mathrm{OH} \longrightarrow{ }^{\bullet} \mathrm{NO}_{2}+\mathrm{OH}^{-}
$$

Mark et al. [25] observed nitrite scavenging effects on ${ }^{\circ} \mathrm{OH}$ at a concentration of $6 \times 10^{-6} \mathrm{M}$, which was about $1 / 10$ of our usage, under UV, suggesting that nitrite addition in the photolytic system in our study might also carry out a scavenging function of hydroxyl radicals in this system.

3.4. Effects of Sulfate. With the addition of $1 \mathrm{mM}$ and $5 \mathrm{mM}$ sulfate, the first-order kinetic constant varied slightly from $0.071\left(R^{2}=0.98\right)$ to $0.054\left(R^{2}=0.95\right)$ and $0.057\left(R^{2}=0.96\right)$ (Table 1$)$, respectively. Sulfate in a photodegradation solution can cause the following reaction [31]:

$$
\mathrm{SO}_{4}{ }^{2-}+{ }^{\bullet} \mathrm{OH}+\mathrm{H}^{+} \longrightarrow \mathrm{SO}_{4}^{-}+\mathrm{H}_{2} \mathrm{O}
$$

However, the quenching role of sulfate was less effective when compared with other anions like carbonate [28]. This was also true in our study. Only a little decreasing trend was observed for the rate constants between the nonaddition and the treatments with addition of $1 \mathrm{mM}$ or $5 \mathrm{mM}$ sulfate.

3.5. Effects of Bicarbonate. The first-order kinetic constants of the photodegradation of sulfadiazine were decreased to 0.046 $\left(R^{2}=0.96\right), 0.042\left(R^{2}=0.93\right)$, and $0.017\left(R^{2}=0.89\right)$ with the addition of $11.9,2.4$, and $0.5 \mathrm{mM}$ bicarbonate, respectively, as shown in Table 1, indicating an inhibitory effect of bicarbonate on photolytic degradation of sulfadiazine, which has also 
been reported for photolytic or photocatalytic degradation of nonylphenol and 2-chlorobiphenyl [32, 33]. Bicarbonate can act as a scavenger of ${ }^{\bullet} \mathrm{OH}$, the main mechanism of which is as follows [34]:

$$
\mathrm{HCO}_{3}{ }^{-}+{ }^{\bullet} \mathrm{OH} \longrightarrow \mathrm{CO}_{3}{ }^{-\bullet}+\mathrm{H}_{2} \mathrm{O}
$$

The radical $\mathrm{CO}_{3}{ }^{-\bullet}$ is also an oxidant but less active than ${ }^{\circ} \mathrm{OH}$ $[33,34]$. However, although less reactive, radicals generated in such ways may be more persistent in natural environment and help the slow but sustained removal of pollutants. For example, Schwarzenbach et al. [35] argued that concentrations of steady-state $\mathrm{CO}_{3}{ }^{-\bullet}$ in sunlit surface water were estimated to be two orders higher than that of ${ }^{\bullet} \mathrm{OH}$ radicals, which also plays an important role in removal of environmental organic chemicals, especially pollutants.

All rate constants in the presence of bicarbonate were lower than those in the presence of sulfate, suggesting that bicarbonate has a higher quenching effect on hydroxyl radical than sulfate. However, the least bicarbonate addition in this study resulted in the lowest rate constant. Although most studies demonstrated that the rate constant decreased with increasing concentration of bicarbonate [36, 37], as expected from the scavenging mechanism, some different phenomena were also reported in some studies. Zhang et al. [38] found that the photodegradation rate of reactive brilliant orange $\mathrm{K}$ $\mathrm{R}$ catalyzed by $\mathrm{P} 25 \mathrm{TiO}_{2}$ decreased significantly when the conductivity increased from 0.5 to 3.1 or $12.3 \mathrm{mS} \cdot \mathrm{cm}^{-1}$ owing to the existence of bicarbonate but did not further decrease significantly when the conductivity arrived at $24.1 \mathrm{mS} \cdot \mathrm{cm}^{-1}$ or at $47.2 \mathrm{mS} \cdot \mathrm{cm}^{-1}$. The results might imply that increasing bicarbonate amounts generated more carbonate radicals which compensate the loss of the hydroxyl radicals, since both sulfur atom and benzene ring exist commonly in the molecular structure of sulfadiazine and reactive brilliant orange K-R [38]. This might explain the less extent inhibition of higher levels of bicarbonate observed in our study.

3.6. Effects of $p H$ Value. As shown in Table 1, the initial $\mathrm{pH}$ 4.52 resulted in lowest $k$ of $0.046\left(R^{2}=0.91\right)$, while at $\mathrm{pH} 6.98$ and $\mathrm{pH} 8.20 k$ was $0.065\left(R^{2}=0.98\right)$ and 0.057 $\left(R^{2}=0.94\right)$, respectively. Sulfadiazine can be dissociated to both cationic and anionic forms with $p K a$ values of 1.57 and 6.50, respectively [39]. In our study, sulfadiazine existed mostly as neutral and anionic forms at $\mathrm{pH} 4.52$ and $\mathrm{pH} 8.20$, respectively, and as a mixture of both species but dominated by the anionic form, at $\mathrm{pH}$ 6.98. Therefore, different reaction rates of ${ }^{\bullet} \mathrm{OH}$ with various existence form of sulfadiazine may be one explanation for the lower rate constant under $\mathrm{pH} 4.52$. However, the discrepancy was not significant, suggesting that the solution acidity played a less important role in this photodegradation.

\section{Conclusions}

Sulfadiazine was photolyzed at a high rate by irradiation of UV $365 \mathrm{~nm}(300 \mathrm{~W})$, with a half-life of $9.76 \mathrm{~min}$ as air was introduced in. The existence of nitrogen, $\mathrm{SO}_{4}{ }^{2-}, \mathrm{HCO}_{3}{ }^{-}$, and $\mathrm{NO}_{2}{ }^{-}$inhibited this reaction, while $\mathrm{H}_{2} \mathrm{O}_{2}, \mathrm{NO}_{3}{ }^{-}$enhanced the reaction rate. The neutral $\mathrm{pH}$ value was most beneficial for this photolytic reaction. These phenomena suggest that this reaction is possibly mediated mainly by hydroxyl radicals. Results of this study will also provide valuable reference for the design and running of the system of pretreatment by UV photodegradation of such chemicals.

\section{Competing Interests}

The authors declare that there are no competing interests regarding the publication of this paper.

\section{References}

[1] A. K. Sarmah, M. T. Meyer, and A. B. A. Boxall, "A global perspective on the use, sales, exposure pathways, occurrence, fate and effects of veterinary antibiotics (VAs) in the environment," Chemosphere, vol. 65, no. 5, pp. 725-759, 2006.

[2] T. X. Le and Y. Munekage, "Residues of selected antibiotics in water and mud from shrimp ponds in mangrove areas in Viet Nam," Marine Pollution Bulletin, vol. 49, no. 11-12, pp. 922-929, 2004.

[3] D. G. Capone, D. P. Weston, V. Miller, and C. Shoemaker, "Antibacterial residues in marine sediments and invertebrates following chemotherapy in aquaculture," Aquaculture, vol. 145, no. 1-4, pp. 55-75, 1996.

[4] T. Christian, R. J. Schneider, H. A. Färber, D. Skutlarek, M. T. Meyer, and H. E. Goldbach, "Determination of antibiotic residues in manure, soil, and surface waters," Acta Hydrochimica et Hydrobiologica, vol. 31, no. 1, pp. 36-44, 2003.

[5] S. Thiele-Bruhn and I.-C. Beck, "Effects of sulfonamide and tetracycline antibiotics on soil microbial activity and microbial biomass," Chemosphere, vol. 59, no. 4, pp. 457-465, 2005.

[6] B. G. Bradel, W. Preil, and H. Jeske, "Remission of the freebranching pattern of Euphorbia pulcherrima by tetracycline treatment," Journal of Phytopathology, vol.148, no. 11-12, pp. 587590, 2000.

[7] L. Wollenberger, B. Halling-Sørensen, and K. O. Kusk, “Acute and chronic toxicity of veterinary antibiotics to Daphnia magna," Chemosphere, vol. 40, no. 7, pp. 723-730, 2000.

[8] L. Migliore, G. Brambilla, P. Casoria, C. Civitareale, S. Cozzolino, and L. Gaudio, "Effect of sulphadimethoxine contamination on barley (Hordeum distichum L., Poaceae, Liliopsida)," Agriculture, Ecosystems and Environment, vol. 60, no. 2-3, pp. 121-128, 1996.

[9] S. Thiele-Bruhn, "Pharmaceutical antibiotic compounds in soils-a review," Journal of Plant Nutrition and Soil Science, vol. 166, no. 2, pp. 145-167, 2003.

[10] P. Sukul and M. Spiteller, "Sulfonamides in the environment as veterinary drugs," Reviews of Environmental Contamination and Toxicology, vol. 187, pp. 67-101, 2006.

[11] A. B. A. Boxall, L. A. Fogg, P. A. Blackwell, P. Kay, E. J. Pemberton, and A. Croxford, "Veterinary medicines in the environment," Reviews of Environmental Contamination and Toxicology, vol. 180, pp. 1-91, 2004.

[12] K. M. Doretto, L. M. Peruchi, and S. Rath, "Sorption and desorption of sulfadimethoxine, sulfaquinoxaline and sulfamethazine antimicrobials in Brazilian soils," Science of the Total Environment, vol. 476-477, pp. 406-414, 2014.

[13] A. B. A. Boxall, P. Blackwell, R. Cavallo, P. Kay, and J. Tolls, "The sorption and transport of a sulphonamide antibiotic in soil systems," Toxicology Letters, vol. 131, no. 1-2, pp. 19-28, 2002. 
[14] F. Ingerslev and B. Halling-Sorensen, "Biodegradability properties of sulfonamides in activated sludge," Environmental Toxicology and Chemistry, vol. 19, no. 10, pp. 2467-2473, 2000.

[15] P. Sukul, M. Lamshöft, S. Zühlke, and M. Spiteller, "Photolysis of ${ }^{14} \mathrm{C}$-sulfadiazine in water and manure," Chemosphere, vol. 71, no. 4, pp. 717-725, 2008.

[16] A. L. Boreen, W. A. Arnold, and K. McNeill, "Triplet-sensitized photodegradation of sulfa drugs containing six-membered heterocyclic groups: identification of an $\mathrm{SO}_{2}$ extrusion photoproduct," Environmental Science and Technology, vol. 39, no. 10, pp. 3630-3638, 2005.

[17] F. Jiang, Z. Zheng, Z. Xu, and S. Zheng, "Preparation and characterization of $\mathrm{SiO}_{2}$-pillared $\mathrm{H}_{2} \mathrm{Ti}_{4} \mathrm{O}_{9}$ and its photocatalytic activity for methylene blue degradation," Journal of Hazardous Materials, vol. 164, no. 2-3, pp. 1250-1256, 2009.

[18] A. L. Boreen, W. A. Arnold, and K. McNeill, "Photochemical fate of sulfa drugs in then aquatic environment: sulfa drugs containing five-membered heterocyclic groups," Environmental Science and Technology, vol. 38, no. 14, pp. 3933-3940, 2004.

[19] M. G. Gonzalez, E. Oliveros, M. Wörner, and A. M. Braun, "Vacuum-ultraviolet photolysis of aqueous reaction systems," Journal of Photochemistry and Photobiology C: Photochemistry Reviews, vol. 5, no. 3, pp. 225-246, 2004.

[20] L. Zang, C.-Y. Liu, and X.-M. Ren, "Photochemistry of semiconductor particles. Part 4.-effects of surface condition on the photodegradation of 2,4-dichlorophenol catalysed by $\mathrm{TiO}_{2}$ suspensions," Journal of the Chemical Society, Faraday Transactions, vol. 91, no. 5, pp. 917-923, 1995.

[21] C. B. Almquist and P. Biswas, "The photo-oxidation of cyclohexane on titanium dioxide: an investigation of competitive adsorption and its effects on product formation and selectivity," Applied Catalysis A: General, vol. 214, no. 2, pp. 259-271, 2001.

[22] M. Muruganandham and M. Swaminathan, "Photochemical oxidation of reactive azo dye with UV- $\mathrm{H}_{2} \mathrm{O}_{2}$ process," Dyes and Pigments, vol. 62, no. 3, pp. 269-275, 2004.

[23] Q. Hu, C. Zhang, Z. Wang et al., "Photodegradation of methyl tert-butyl ether (MTBE) by $\mathrm{UV} / \mathrm{H}_{2} \mathrm{O}_{2}$ and $\mathrm{UV} / \mathrm{TiO}_{2}$," Journal of Hazardous Materials, vol. 154, no. 1-3, pp. 795-803, 2008.

[24] C. Minero, S. Chiron, G. Falletti et al., "Photochemincal processes involving nitrite in surface water samples," Aquatic Sciences, vol. 69, no. 1, pp. 71-85, 2007.

[25] G. Mark, H.-G. Korth, H.-P. Schuchmann, and C. Von Sonntag, "The photochemistry of aqueous nitrate ion revisited," Journal of Photochemistry and Photobiology A: Chemistry, vol. 101, no. 2-3, pp. 89-103, 1996.

[26] M. V. Shankar, S. Nélieu, L. Kerhoas, and J. Einhorn, "Photoinduced degradation of diuron in aqueous solution by nitrites and nitrates: kinetics and pathways," Chemosphere, vol. 66, no. 4, pp. 767-774, 2007.

[27] I. K. Konstantinou, A. K. Zarkadis, and T. A. Albanis, "Photodegradation of selected herbicides in various natural waters and soils under environmental conditions," Journal of Environmental Quality, vol. 30, no. 1, pp. 121-130, 2001.

[28] Z. Zainal, C. Y. Lee, M. Z. Hussein, A. Kassim, and N. A. Yusof, "Effect of supporting electrolytes in electrochemically-assisted photodegradation of an azo dye," Journal of Photochemistry and Photobiology A: Chemistry, vol. 172, no. 3, pp. 316-321, 2005.

[29] M. W. Lam, K. Tantuco, and S. A. Mabury, "PhotoFate: a new approach in accounting for the contribution of indirect photolysis of pesticides and pharmaceuticals in surface waters," Environmental Science and Technology, vol. 37, no. 5, pp. 899907, 2003. hydroxyl radicals upon irradiation of natural water samples," Environmental Science and Technology, vol. 40, no. 12, pp. 37753781, 2006

[31] K.-H. Wang, Y.-H. Hsieh, C.-H. Wu, and C.-Y. Chang, “The pH and anion effects on the heterogeneous photocatalytic degradation of o-methylbenzoic acid in $\mathrm{TiO}_{2}$ aqueous suspension," Chemosphere, vol. 40, no. 4, pp. 389-394, 2000.

[32] M. Neamţu and F. H. Frimmel, "Photodegradation of endocrine disrupting chemical nonylphenol by simulated solar UVirradiation," Science of the Total Environment, vol. 369, no. 1-3, pp. 295-306, 2006.

[33] Y. Wang, C.-S. Hong, and F. Fang, "Effect of solution matrix on $\mathrm{TiO}_{2}$ photocatalytic degradation of 2-chlorobiphenyl," Environmental Engineering Science, vol. 16, no. 6, pp. 433-440, 1999.

[34] R. Andreozzi, V. Caprio, A. Insola, and R. Marotta, "Advanced oxidation processes (AOP) for water purification and recovery," Catalysis Today, vol. 53, no. 1, pp. 51-59, 1999.

[35] R. P. Schwarzenbach, P. M. Gschwend, and D. M. Imboden, "Indirect photolysis: reactions with photooxidants in natural waters and in the atmosphere," in Environmental Organic Chemistry, pp. 655-686, John Wiley \& Sons, New Jersey, NJ, USA, 2002.

[36] I. Gultekin and N. H. Ince, "Degradation of reactive azo dyes by $\mathrm{UV} / \mathrm{H}_{2} \mathrm{O}_{2}$ : impact of radical scavengers," Journal of Environmental Science and Health. Part A, Toxic/Hazardous Substances \& Environmental Engineering, vol. 39, no. 4, pp. 1069-1081, 2004.

[37] W. Zhang, X. Xiao, T. An et al., "Kinetics, degradation pathway and reaction mechanism of advanced oxidation of 4-nitrophenol in water by a $\mathrm{UV} / \mathrm{H}_{2} \mathrm{O} 2$ process," Journal of Chemical Technology and Biotechnology, vol. 78, no. 7, pp. 788794, 2003.

[38] W. Zhang, T. An, M. Cui, G. Sheng, and J. Fu, "Effects of anions on the photocatalytic and photoelectrocatalytic degradation of reactive dye in a packed-bed reactor," Journal of Chemical Technology and Biotechnology, vol. 80, no. 2, pp. 223-229, 2005.

[39] P. Sukul, M. Lamshöft, S. Zühlke, and M. Spiteller, "Sorption and desorption of sulfadiazine in soil and soil-manure systems," Chemosphere, vol. 73, no. 8, pp. 1344-1350, 2008. 

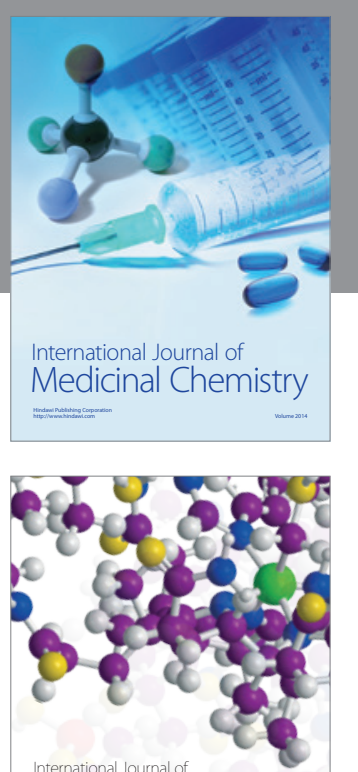

Carbohydrate Chemistry

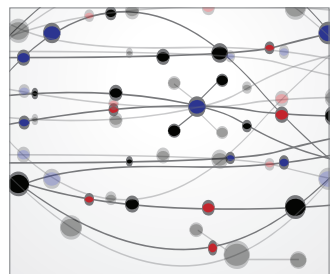

The Scientific World Journal
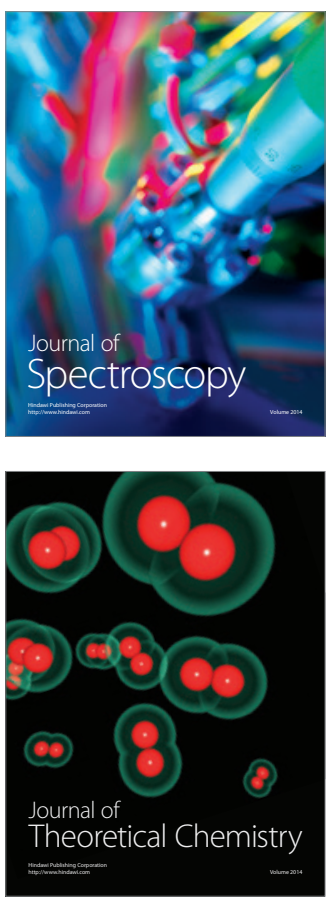
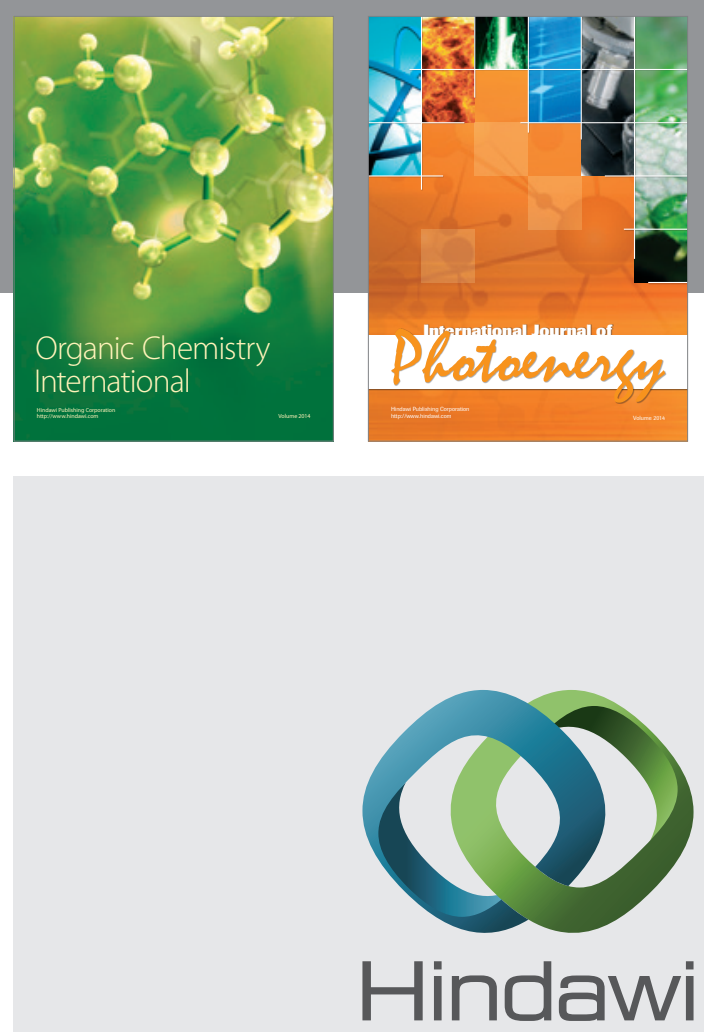

Submit your manuscripts at

http://www.hindawi.com

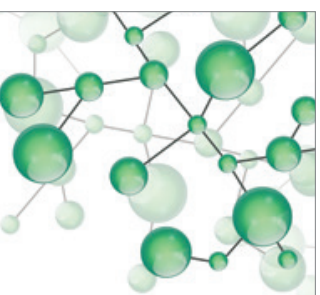

International Journal of

Inorganic Chemistry

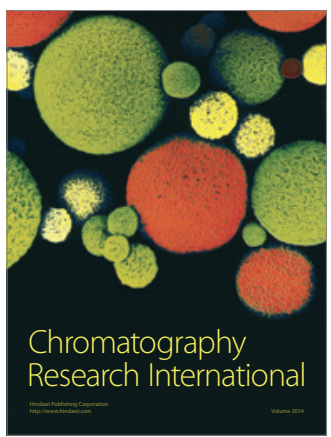

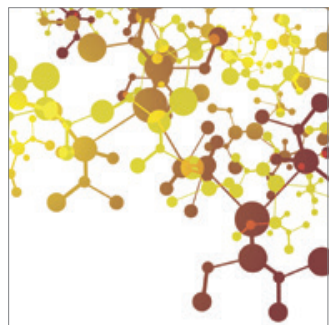

Applied Chemistry
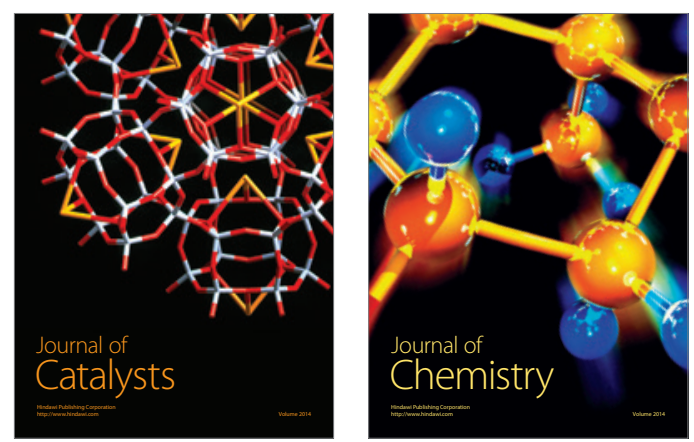
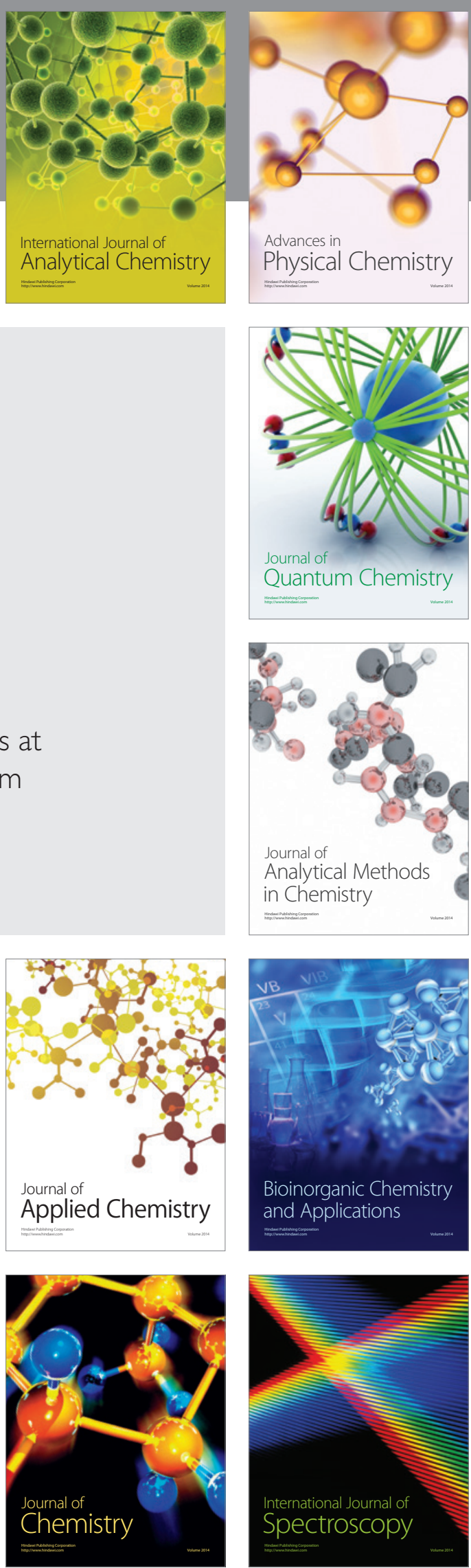